\title{
Mediações e pesquisas na área de comunicação e saúde
}

\section{Mediations and researches in the field of communication and health}

\section{Mediaciones y investigaciones en el campo de la comunicación y de la salud}

Antonio Carlos Ferreira Vianna ${ }^{1, a}$

antonio.cferreira@saude.gov.br | https://orcid.org/oooo-0001-7160-6200

${ }^{1}$ Ministério da Saúde, Assessoria de Comunicação. Rio de Janeiro, RJ, Brasil.

a Mestrado em Mídia e Cotidiano pela Universidade Federal Fluminense.

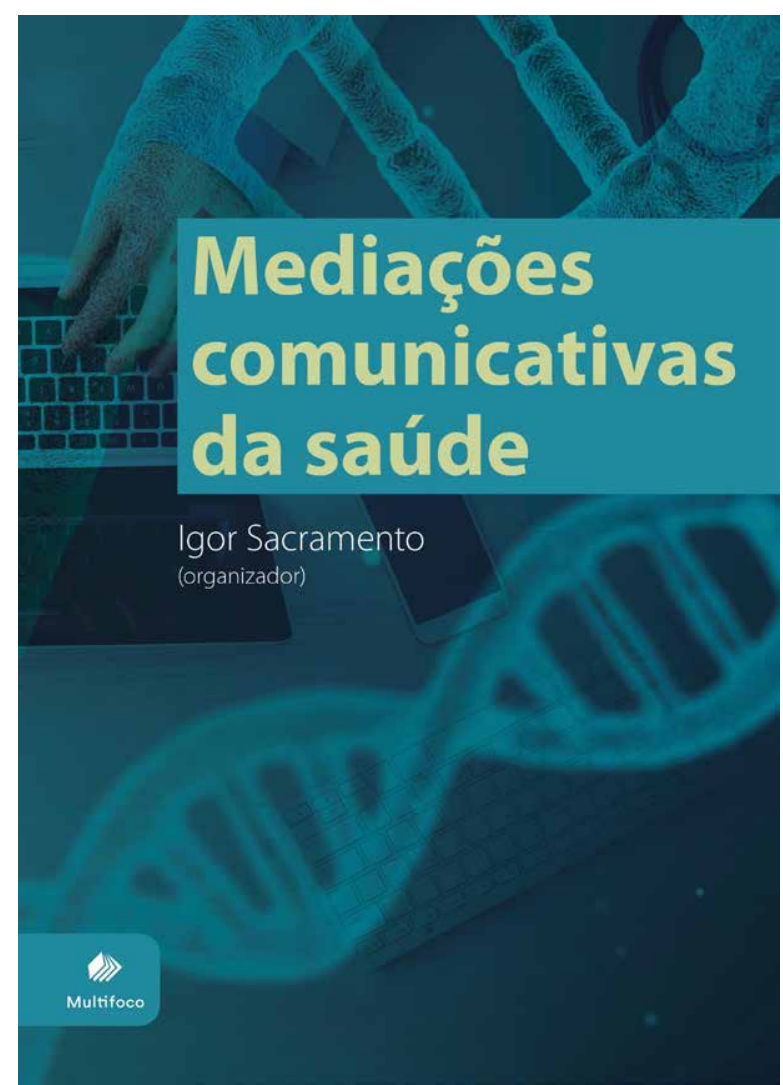

Resenha do livro: Sacramento I, organizador. Mediações comunicativas da saúde. Rio de Janeiro: Multifoco; 2017.

Palavras-chave: Mediações; Comunicação; Democracia; Saúde; Tecnologias digitais. Keywords: Mediations; Communication; Democracy; Health; Digital technologies.

Palabras clave: Mediaciones; Comunicación; Democracia; Salud; Tecnologías digitales. 
Durante muito tempo, as pesquisas na área de comunicação se concentraram em estudar os efeitos que as mensagens produzidas pelos meios exerciam sobre os sujeitos, sem se preocupar, necessariamente, com as apropriações que as pessoas faziam do conteúdo dessas mensagens. A partir disso, a obra Mediações comunicativas da saúde, organizada por Igor Sacramento, propõe o desafio de deslocar o foco dos dispositivos de mídia para se pensar a comunicação por meio das mediações culturais, sobretudo em pesquisas na área de saúde. De acordo com o organizador, o objetivo do livro é explorar um "conjunto diversificado de abordagens de estudos de mediações e suas implicações na pesquisa em comunicação e saúde"

Antes de apresentar esses diferentes enfoques, o organizador traça uma breve introdução sobre o desenvolvimento das concepções de mediação aplicadas ao campo da comunicação. Parte-se da filosofia de Friedrich Hegel, para quem todos os objetos são apreendidos mediadamente e imediatamente, ou seja, tudo que chegar ao nosso conhecimento imediato apreenderemos a partir de um conjunto de informações prévias, que já estão armazenadas em nossa consciência.

O conceito hegeliano de mediação foi sistematizado por Theodor $\mathrm{Adorno}^{2}$, que entendia o termo como o resultado objetivo de uma relação social e não como um processo de comunicação. Por isso, segundo o teórico marxista, é preciso analisar as condições sociais que permitem a existência dos produtos culturais para, em seguida, verificar a padronização dos indivíduos como uma consequência da produção em massa. Esta concepção é utilizada em alguns artigos da obra organizada por Sacramento, que relacionam o processo de medicalização da vida com a indústria cultural.

A partir da perspectiva de que uma ideologia seria reproduzida pelos meios de comunicação, desenvolvida por Adorno, Louis Althusser concebeu "uma conceituação a-histórica de ideologia baseada na reprodução social, considerando a estrutura social como máquina autossuficiente de produção ideológica”’. Já Raymond Williams reformula a noção de mediação ao estabelecer uma relação entre o produto cultural e suas condições históricas. Para o pensador inglês, é preciso enxergar a comunicação de maneira indissolúvel no processo social, o que possibilita articular, por exemplo, os diversos segmentos da indústria da saúde com suas determinações sociais e materiais ${ }^{4}$.

O conceito de mediação proposto por Williams é criticado por Muniz Sodré, que considera que a proposta não abarca a totalidade do processo de comunicação. Seria preciso pensar um conceito que "descreve o funcionamento articulado das tradicionais instituições sociais e dos indivíduos com a mídia"5. O nome deste conceito proposto por Sodré é midiatização; ele o utiliza ao estudar as mediações culturais e comunicativas da vida em sociedade para explicar seus processos e suas imbricações.

No âmbito do jornalismo, também é preciso considerar a teoria do campo, de Pierre Bourdieu, que demonstra uma visão tão compartimentada da sociedade a ponto de justificar agentes especializados em mediações (os jornalistas, por exemplo). Para Bourdieu, a mediação seria um modo de transformação das relações sociais, pois permitiria a recriação da realidade ${ }^{6}$. Entretanto, foi a reorientação epistemológica de Jesús Martín-Barbero que marcou a principal transformação nos estudos da nossa área, ao retirar o foco do objeto (os meios) para observar os processos culturais nos quais a comunicação ocorre: as mediações.

O artigo 'Mediação e saúde: a importância da comunicação na gestão da formação de residentes no Brasil', de Wilson Couto Borges e Adriana Cavalcanti de Aguiar, explora, na primeira parte do livro, os conceitos de circularidade cultural (a partir das formulações de Mikhail Bakhtin e Carlo Ginzburg) e de mediação (com ênfase nos estudos de Jésus Martin-Barbero) em pesquisas sobre a formação de profissionais pelos programas de residência de quatro regiões do Brasil. $\mathrm{O}$ artigo busca demonstrar a centralidade da cultura no processo de formação das identidades e a importância da comunicação na formação de residentes no Brasil.

Para os autores, o papel da cultura é considerado central no processo de formação social, mas "isso não significa dizer que outros valores, mais ou menos distantes, tanto no tempo quanto no espaço, não dialoguem com essa estrutura produzida"8. Como um sistema cultural precisa de processos mais estáveis para que as 
transmissões de conhecimento acumulado possam ocorrer, a comunicação irá emergir não apenas como processo cultural, mas como possibilidade de articulação e de organização da vida em sociedade.

Não se trata, de acordo com eles, de conceber a comunicação como transferência de conhecimento acumulado entre interlocutores, mas sim de compreender a dimensão da mediação no compartilhamento de experiências e informações dos múltiplos atores sociais envolvidos na formação dos residentes no Brasil.

A aplicação da noção de mediação, concebida por Jésus Martin-Barbero, foi ainda mais detalhada no artigo 'O mapa das mediações comunicativas da cultura: cartografando a pesquisa', de Ana Carolina Escosteguy e Lírian Sifuentes, que também integra a primeira parte da obra 'Mediações comunicativas da saúde', denominada de 'A questão das mediações'. As autoras dividem em dois momentos a aplicação do pensamento de Barbero no Brasil: o primeiro seria aquele em que se deu a circulação do mapa das mediações comunicativas da cultura no Brasil; e o segundo abrange a etapa em que se passou a reconhecer a perspectiva do mapa como um circuito comunicativo que constitui uma visão integrada de produção, circulação e recepção.

Ao analisar diversas aplicações do mapa de Barbero, em pesquisas de comunicação e saúde, Escosteguy e Sifuentes percebem que a grande maioria dos trabalhos concentra a atenção nos estudos de recepção. Há, entretanto, outras perspectivas, que pensam a mediação como um processo que vai além do modelo 'de cima para baixo, ou de baixo para cima', e consideram as suas múltiplas práticas. É o caso do artigo de Ana Valéria Machado Mendonça, Grasiela de Sousa Pereira, Mariella Silva de Oliveira-Costa e Maria Fátima de Sousa denominado 'Fala, Agente! Saberes e práticas comunicacionais nos territórios de atuação'. As autoras analisaram o depoimento de agentes comunitários de saúde de diversos estados do país, a partir das definições de mediação individual (que surge a partir de traços culturais do indivíduo) e mediação situacional (onde há interação), elaborada por Guillermo Orozco Gómez.

Para elas, o receptor não é só o decodificador de mensagens, mas produtor de novos significados, conforme seus valores sociais. Os agentes de saúde atuariam como mediadores culturais entre a literatura da medicina e o conhecimento popular, o que faz da mediação um processo que abrange o conteúdo e a forma das relações desempenhadas.

No âmbito do Sistema Único de Saúde (SUS), talvez a maneira mais eficaz de se entender a decodificação das mensagens, pelos receptores, é conversar com os usuários que fazem uso dos serviços. Foi nisso que se concentrou o artigo 'Diálogo e vínculo: as práticas comunicacionais de mediação na garantia do direito à saúde', de Juliana Lofêgo e Roseni Pinheiro, com base em pesquisa realizada com mulheres que realizavam o controle do câncer de colo de útero no estado do Acre. As autoras verificaram, nos gestores do SUS, uma concepção limitada da comunicação, na qual as informações deveriam ser transmitidas apenas de cima para baixo.

O texto de Lofêgo e Pinheiro se encontra já na segunda parte da obra 'Mediações comunicativas da saúde', chamada de 'Políticas e práticas'. Para elas, a participação das usuárias do SUS na construção e acompanhamento das políticas públicas de saúde contribuiria para um sistema mais eficiente, além de garantir o exercício de cidadania dessas mulheres. Desta forma, pensar nas múltiplas práticas de mediação nos leva a olhar para a comunicação como pilar fundamental para o exercício da cidadania e como garantia do direto à saúde, assegurado na Constituição Federal de 1988. Os três artigos da referida segunda parte se dedicam a tal abordagem.

A democratização da radiodifusão como elemento central para garantia da cidadania e saúde no Brasil é o tema da contribuição de Rodrigo Murtinho e Luiz Felipe Stevanim no artigo 'Políticas de comunicação, cidadania e saúde no Brasil contemporâneo'. Os autores analisam as tensões entre o público e o privado, além de proporem políticas de comunicação que não estejam centradas apenas nas ações do Estado.

Para garantir a cidadania como eixo estruturante dos direitos à saúde, por meio da democratização da comunicação, Murtinho e Stevanim consideram dois pilares como essenciais: o reconhecimento das rádios 
comunitárias e o incentivo à comunicação pública. A preocupação em construir políticas de saúde, sem excluir determinadas vozes da sociedade, também se faz presente no trabalho de Inesita Soares de Araujo e Wilma Madeira da Silva, que analisaram o tempo de fala, as disposições físicas, as regras discursivas, os temas pré-determinados e outras estratégias de poder na XII Conferência Nacional de Saúde (CNS) e na III Conferência Nacional de Saúde Indígena (CNSI).

No artigo 'Estratégias discursivas e (des)colonização da enunciação: as Conferências de Saúde como campos de batalha', Araujo e Silva reconhecem o alto potencial das conferências como promotoras de cidadania e apontam caminhos para se promover novas ordens de discursos, capazes de pôr efetivamente em prática o exercício democrático. Com isso, as autoras esperam debates mais plurais na construção de políticas de saúde de abrangência nacional.

A disputa pelo lugar de fala, que se verifica nos congressos de saúde, também pode ser observada em outros campos. Para Pierre Bourdieu, na mediação entre os campos, o que tem funções sociais de maior importância é o jornalismo, que possui a capacidade de reordenar a esfera pública ${ }^{9}$. Neste contexto, a terceira parte do livro organizado por Sacramento, intitulada como 'Discursos Jornalísticos', traz três contribuições sobre esta temática.

As notícias que relataram o surgimento da dengue, em 1986, e da zika, em 2015, nas páginas do jornal O Globo, foram tema do artigo 'A emergência das epidemias de dengue e zika em O Globo', de Janine Cardoso, Igor Sacramento e Izamara Bastos Machado, que teve como objetivo analisar a participação do jornalismo na construção narrativa de eventos epidemiológicos. Para eles, pesquisar o jornalismo a partir da cultura permite conduzir a investigação para as mediações. Como os próprios veículos jornalísticos são dotados de determinadas posturas político-ideológicas, escolhas editoriais, modos de cobertura, entre outros aspectos - , pelo fato de serem moldados por mediações de diversas esferas - , as narrativas jornalísticas sobre estas epidemias são capazes de reconfigurar determinadas ações e práticas, nos campos da política e da saúde, para responder às demandas geradas pelo próprio jornal, como se fossem exigências da população.

As matérias de O Globo também serviram de exemplo para Iara Bastos Campos e Wedencley Alves demonstrarem como o 'psicopata' aparecia sendo um sujeito carente de cuidados médicos, até os anos 1990, e depois a relação entre psicopatia e criminalidade passou a ser realçada pelas notícias do jornal. No artigo 'Nomear o mal: sentidos de psicopatia e sujeito psicopata no jornal O Globo', os autores abordam os sentidos produzidos pelas doenças, a partir do momento em que elas são designadas. De acordo com eles, não se trata apenas de uma questão de nomenclatura, uma vez que a designação dos males se torna um acontecimento capaz de levar sujeitos sociais à compaixão, mas também a medos e angústias em relação ao outro, "não raramente tendo por efeito a estigmatização de indivíduos e grupos sociais". ${ }^{10}$

Ainda na terceira parte da obra, o artigo 'A saúde mediada pela televisão: o caso do Jornal Nacional', de Fernando Lefèvre e Eduardo Caron, discute as interações entre médicos (especialistas) e público leigo (telespectadores), por meio de jornalistas que atuam como mediadores. O trabalho aponta para uma reificação da saúde através de matérias jornalísticas que privilegiam certos temas, em detrimento de outros, com o objetivo de desvalorizar o SUS e transformar o sujeito em dependente de mercadorias.

A partir da contribuição de Lefèvre e Caron, é possível imaginar como esse sujeito vai se comportar quando navegar por uma infinita rede de informações, na qual as possibilidades para o consumo das mais diversas mercadorias, relacionadas à saúde, multiplicam-se a cada dia. Na quarta e última seção do livro aqui resenhado, intitulada 'Internet e tecnologias digitais', Helena Jacob discute a transformação de sentidos sobre a alimentação nas redes sociais, a partir dessa concepção de sujeitos transformados em dependentes de mercadorias.

No artigo 'Alimentação e redes sociais: a saúde nas mediações da linguagem fitness', Jacob analisa como a obrigação de cuidar dos seus próprios corpos resulta em uma linguagem (fitness) que impacta fortemente a cultura da alimentação em todo o mundo e influencia o mercado e a indústria de alimentos. 
Além da contribuição de Helena Jacob, outros três artigos dessa última parte da obra tratam de assuntos relacionados à internet e à saúde. Paulo Roberto Vasconcellos-Silva e Luis David Castiel exploram a ampla divulgação, na grande rede, de produtos e serviços considerados vicários. No artigo 'Mercado e consumo de panaceias na internet: a cura silvestre para o bom selvagem', os autores elaboram uma lista de endereços eletrônicos que prometem, em sua maioria, curar diferentes tipos de câncer com procedimentos não reconhecidos pelas instituições oficiais.

Paulo Roberto Vasconcellos-Silva e Luis David Castiel ressaltam como as 'terapias fraudulentas' disseminadas na internet se tornaram significativas na sociedade contemporânea, o que nos mostra mais um exemplo de transformação da noção de saúde pela comunicação - ainda que este caso se concentre na centralidade do consumo, uma vez que o mercado se alinha à demanda desses métodos paracientíficos.

Já Marcia Rodrigues Lisboa propõe uma pesquisa qualitativa acerca das formas de apropriação de adolescentes, moradores de uma comunidade pobre, sobre notícias relacionadas ao cuidado e ao risco à saúde. Em 'Quem acessa tanta notícia? A presença do jornalismo no cotidiano de adolescentes residentes em uma favela carioca', ela argumenta que as interações mediadas e as miditizadas são inseparáveis quando se pesquisa o contexto da recepção de informações na vida cotidiana destes jovens.

O livro 'Mediações comunicativas da saúde' termina com o artigo 'A busca pela 'reprogramação' do corpo e a performance do bem-estar no contexto da comunicação digital', no qual Erika Oikawa nos mostra como as ferramentas de comunicação contemporâneas contribuem para que os indivíduos gerenciem seus corpos como se fossem uma empresa, ou seja, perseguindo a otimização da performance tida como ideal, com apoio de psicotrópicos e de aplicativos móveis digitais.

Oikawa ressalta que o automonitoramento de dados não é um fenômeno recente. A novidade agora é que, com o auxílio dos aplicativos, é possível monitorar praticamente todas as atividades diárias (de gastos financeiros à atividade sexual). Com isso, a otimização do corpo e da mente, que se restringia a ambientes hospitalares e laboratórios científicos, hoje se estende por todo o corpo social, tendo como grande vetor os processos comunicacionais.

\section{Referências}

1. Sacramento I, organizador. Mediações comunicativas da saúde. Rio de Janeiro: Multifoco; 2017.

2. Adorno TW. Teses sobre a sociologoia da arte. In: Cohn G, organizador. Theodor W. Adorno. São Paulo: Ática; 1986.

3. Althusser L. Aparelhos ideológicos de Estado. Rio de Janeiro: Graal; 1987.

4. Williams R. Cultura. Rio de Janeiro: Paz e Terra; 2000.

5. Sodré M. A ciência do comum: notas para o método comunicacional. Petrópolis: Vozes; 2014.

6. Bordieu P. As regras da arte: gênese e estrutura do campo literário. São Paulo: Companhia das Letras; 1996.

7. Martín-Barbero J. Ofício de cartógrafo: travesia latino-americana da comunicação na cultura. São Paulo: Loyola; 2004.

8. Borges WC, Aguiar AC. Mediação e saúde: a importância da comunicação na gestão da formação de residentes no Brasil. In: Sacramento I, organizador. Mediações comunicativas da saúde. Rio de Janeiro: Multifoco; 2017. p. 85-118.

9. Bordieu P. The political field, the social sciece field and the journalistic field. In: Benson R, Neveu E, organizadores. Bordieu and the journalistic field. Malden: Polity Press, 2005.

10. Campos IB, Alves W. Nomear o mal: sentidos de psicopatia e sujeito psicopata no jornal O Globo. In: Sacramento I, organizador. Mediações comunicativas da saúde. Rio de Janeiro: Multifoco; 2017. p. 271-87. 